\title{
La maternidad glorificada: análisis de los discursos sobre maternidad de mujeres que participan en grupos de crianza respetuosa de la región de Valparaíso, Chile.
}

Glorified maternity: analysis of motherhood discourses from women participating in groups of respectful child rearing in Valparaíso region, Chile.

Daniela Villanueva Aburto*

\section{Resumen}

Hoy más que nunca las mujeres están expuestas a un sinfín de representaciones sociales sobre el género y la familia. En este contexto, emerge con fuerza un nuevo movimiento que busca resignificar la maternidad: se trata de los llamados grupos de crianza respetuosa, los cuales están conformados mayoritariamente por jóvenes madres profesionales. El presente artículo busca comprender la compleja articulación entre maternidad y ciudadanía, entendido como la relación entre lo privado y lo político. Para ello se describen y analizan los discursos sobre maternidad de mujeres que participan en grupos de crianza, de los cuales se extraen dos principales consecuencias: por un lado, la reproducción de los roles tradicionales de género y, por otro, la resistencia que estos discursos plantean al orden social dominante. Todo esto bajo la glorificación de la maternidad como mecanismo para la transformación social.

Palabras clave: discursos, pensamiento maternalista, maternidad, grupos de crianza respetuosa.

\begin{abstract}
Today more than ever women are exposed to unending ambiguous social representations of gender and family. In this context a new movement seeks to resignify motherhood: this movement is about so-called respectful child rearing, which has mainly been assembled by young professional mothers. The following article tries to understand the complex articulation between motherhood and citizenship, understood as the relation between the private and the political. To this end, motherhood discourses are described and analyzed, from which two main consequences are extracted: on the one hand, the reproduction of traditional gender roles and, on the other, the resistance that these discourses pose to the dominant social order. All this under the glorification of motherhood as a mechanism for social transformation.
\end{abstract}

Key words: discourses, maternal thinking, motherhood, groups of respectful child rearing.

Fecha de recepción: 27 de agosto 2015

Fecha de aprobación: 27 de febrero 2017

\footnotetext{
*Socióloga de la Universidad de Valparaíso, Chile. dani.villanueva.aburto@gmail.com
} 


\section{Presentación}

Asistimos a una sociedad en donde lo tradicional convive no sin dificultades con lo moderno. En temas de género, los cambios no son homogéneos ni se producen al unísono: en muchas ocasiones la esfera pública avanza más rápido que la privada, de lo cual se desprende que los cambios en las relaciones de género no siguen una línea recta y ascendente hacia la igualdad. Es cierto que la sociedad chilena se ha vuelto más sensible a las desigualdades de género, sin embargo, la distribución de las responsabilidades familiares y domésticas sigue siendo tarea casi exclusiva de las mujeres (PNUD, 2010).

En los últimos años la maternidad se ha convertido en un tema complejo dando forma a un conjunto de nuevas tensiones y ambivalencias respecto a ella. Por un lado, la sociedad ensalza la maternidad, pero, por otro, su complejidad no ha sido lo suficientemente abordada y valorada por el hecho de pertenecer al llamado "mundo de las mujeres» (Saletti, 2008). En este contexto de tensiones y nuevos desafíos en torno a la maternidad, numerosos actores se han interesado en una nueva problemática: la dificultad que supone ser madre hoy en sociedades tan inestables y absorbentes, poniendo en el tapete la compleja relación entre lo privado y lo público. Específicamente, nuevos movimientos de mujeres buscan resignificar la maternidad aportando nuevas miradas para su comprensión desde una dimensión política: nos referimos a los llamados grupos de crianza respetuosa. Uno de sus principales postulados es que el mundo no sólo se cambia desde el ámbito de la política o las instituciones oficiales, sino que desde el hogar y sus relaciones también es posible forjar una nueva "revolución» capaz de cuestionar diversos elementos de las sociedades actuales, abarcando tanto lo público como lo privado.

En este artículo intentamos abordar los distintos discursos sobre maternidad de mujeres que participan en grupos de crianza de la región de Valparaíso. Identificamos en estos discursos un real poder emancipador que, sin embargo, adquiere diversas complejidades debido a que simboliza la relación existente entre lo tradicional y lo moderno como elemento característico de las sociedades contemporáneas: muchas de las funciones y roles tradicionales de género se siguen reproduciendo, combinándose de manera inédita con los roles modernos. De este modo, mientras muchos tópicos y atribuciones de lo femenino se van desvaneciendo, todo un conjunto de funciones y roles tradicionales perduran; lo cual no se debe solamente a su "atraso cultural», sino más bien a la posibilidad de concordar con los nuevos referentes de la autonomía individual de las mujeres y los imperativos de sentirse realizada (Lipovetsky, 1999).

\section{La maternidad en América Latina}

La maternidad adquiere gran importancia para la construcción de la identidad de género femenina. Tal como señala Sonia Montecino (2001), en nuestro continente la maternidad 
marca muy profundamente las diferencias sociales entre hombres y mujeres y es presentada como "tarea natural» de éstas. Lo anterior tiene su origen en la cultura mariana y apuesta a la reproducción de ciertos valores ligados a lo femenino. Desde los análisis de la religiosidad popular, la imagen de María sufriendo en la cruz por su hijo muerto tendría un valor crucial para la transformación social y también para la dignificación y participación de la mujer, puesto que todas las cualidades de mujer quedarían recogidas en ella: gratitud, amor, solidaridad y cuidado. De tal modo, María es reinterpretada como una fuente de liberación tanto para la sociedad como para las mujeres.

Para comprender la forma en que se articulan los discursos de las mujeres que participan en grupos de crianza, es importante considerar cómo los diversos movimientos de mujeres, a lo largo de la historia latinoamericana, han puesto en el centro la lucha de las mujeres y sus derechos ciudadanos y humanos, pero principalmente desde su posición de madres (Zarco, 2011).

Los movimientos sufragistas muchas veces argumentaron que las cualidades «intrínsecas» de las mujeres contribuirían a mejorar la vida política de las sociedades, apelando a un supuesto estatus moral superior. Este pensamiento fue clave al momento de hablar sobre los nuevos derechos de las mujeres, ya que a través de éste se intentó enaltecer su papel a escala nacional, pues, la maternidad exigía respeto en calidad de servicio a la nación mediante la crianza y educación de niños y niñas (Lavrin, 2005). Las feministas latinoamericanas se basaron en la cuestión de la diferencia a través de representaciones idealizadas de la maternidad y el deber conyugal. Mientas que en Europa, las mujeres feministas intentaban alejarse de las imágenes e identidades relacionadas a la familia y la maternidad, en nuestro continente esta corriente fue menos influyente (Molyneux, 2003).

Durante la década de los ochenta y noventa, los movimientos por la vivienda, liderados principalmente por mujeres y concentrados en los barrios populares del continente, exigieron a los gobiernos la legalización de terrenos y ayuda monetaria para la construcción de casas, con el objetivo de entregar mayor bienestar para sus hijos e hijas (Zarco, 2011), esto relacionado a la idea de "vivir dignamente". Por otro lado, durante los setenta y ochenta, y debido a los regímenes militares del Cono Sur, emergieron nuevos movimientos de mujeres madres que lucharon por la defensa de los derechos humanos de sus hijos e hijas desaparecidos o detenidos, cristalizados en el conocido Madres de la Plaza de Mayo. En este sentido,

"Las mujeres resignificaron su maternidad y, a partir de ello, emprendieron sus luchas: ya no era suficiente quedarse en casa y atender a la familia, era necesario salir a la calle e interactuar con el Estado. Cambiaron, así, su estatus "natural" de mujeres-madres por un estatus político. La maternidad se re-conceptualizó como forma de participación social, lo que la hizo política. En otras palabras, estas mujeres politizaron la maternidad" (Zarco, 2011: 234). 
Sería correcto afirmar, entonces, que en nuestro continente los roles de la mujer como esposa y madre se entrecruzan con la historia de la ciudadanía femenina. No obstante, esta identificación con la maternidad no implicó necesariamente una postura política específica: los movimientos maternalistas se asociaron con opciones provenientes desde todo el abanico político, desde izquierdas a derechas. Por ejemplo, en nuestro país, los movimientos de mujeres en los setenta y ochenta se desplegaron desde los movimientos de madres por los derechos humanos de Detenidos Desaparecidos hasta los movimientos de mujeres de barrios acomodados que apoyaban a Pinochet y la Dictadura. Huelga decir que la identidad femenina relacionada a la maternidad varía de acuerdo a categorías como la clase, etnia y edad, pero aun con estos matices la maternidad se configuró como un fuerte referente de movilización femenina (Molyneux, 2003).

Asimismo, recurrentemente en América Latina la maternidad ha sido politizada, vinculándola con ideas nacionalistas y patrióticas. De tal modo, las mujeres, en cuanto madres, han logrado hacerse un espacio en la esfera pública y política. La maternidad, como vemos, aparece como un fuerte componente que moviliza a las mujeres hacia el espacio de lo público y, a su vez, hace a las mujeres diferentes de los hombres, no sólo en el plano de lo biológico, sino también y, por sobre todo, en lo referente a sus valores principales.

En la actualidad, sin embargo, la principal bandera de lucha de los movimientos feministas y de mujeres consiste en alcanzar la igualdad de género, expresando un gran rechazo hacia la idea conservadora de que la identidad de las mujeres se limite exclusivamente a la identificación de éstas como madres. Pero también nos enfrentamos a una interesante paradoja: hoy existen muchas mujeres que ensalzan la maternidad como una nueva manera de generar cambios en las sociedades, apoyadas en discursos medioambientalistas y biológicos (Del Olmo, 2013). Estos movimientos pueden leerse a luz del concepto Efecto de Fusión, acuñado por Gino Germani (1965), el cual permite analizar cómo comportamientos tradicionales -lo que ha sido históricamente la maternidad en cuanto repliega a la mujer al ámbito de lo doméstico y lo privado- son interpretados como comportamientos modernos y "revolucionarios», reforzando los rasgos característicos de la maternidad social, en donde las mujeres llevan consigo la mayoría de las tareas de cuidado de crianza y apego.

Lo anterior se condice con la investigación realizada por el PNUD (2010), en donde se pregunta a los chilenos cuáles son las primeras palabras con las cuales asocia los términos «mujer» y «hombre». Entre los resultados destaca que la representación más frecuente acerca de la mujer es la que la define a partir de los roles que enmarcan la familia y la maternidad, luego sigue la idea de mujer como luchadora, y posteriormente se destaca su carácter positivo en adjetivos como amor, delicada y cariñosa. Sobre las representaciones del hombre encontramos que lo más frecuente son sus rasgos negativos -machista, mentiroso, flojo-, luego aparece como padre y posteriormente como proveedor del hogar. 
La maternidad y la familia siguen siendo las grandes fuentes de la identidad femenina, las cuales incluso trascienden las clases sociales; mientras que el padre sigue destacando por su ausencia en el plano afectivo y familiar. Asimismo, es relevante destacar aquí el concepto de "Matrifocalidad" propuesto por Raymond Smith (en Fernández-Rasines, 2001), el cual señala que los hogares de familias negras centroamericanas tienden a la matrifocalidad por cuanto las mujeres madres adquieren un rol protagónico al interior de la vida familiar y doméstica, generando complejas relaciones con sus hijos/as y entornos, mientras que los padres se mueven en una órbita más bien marginal.

\section{El re-florecimiento de los discursos maternalistas}

La maternidad, a lo largo de la historia occidental, ha sido abordada desde diversas perspectivas: místico-religiosas, biológicas, jurídicas, políticas y antropológicas, entre muchas otras. Algunas de ellas connotan la existencia de una "ley natural» basada en una esencia y capacidad biológica femenina (Iribarne, 2010); otras señalan la maternidad como un regalo de la naturaleza otorgado por Dios (Valladares, 1994); mientras que otras perspectivas más actuales y críticas la reivindican como el resultado de una construcción social y cultural bajo constante cuestionamiento y transformación (Tubert, 2004).

En las últimas décadas se observa el re-surgimiento de una corriente de propuestas feministas muy ligada al empoderamiento de las mujeres en tanto madres, nos referimos al Ilamado feminismo o pensamiento maternalista. Esta corriente nos invita a pensar que lo "privado» sería el lugar de una posible moralidad pública y modelo para la actividad de la ciudadanía (Dietz, 1987), reclamando, además, el rescate de las cualidades "esenciales» de las mujeres, como lo serían la paciencia, la tolerancia, la protección y el cuidado hacia los otros, en contraposición a la competitividad destructiva de los patrones masculinos (Valladares, 1994).

El feminismo maternalista propone reivindicar la capacidad generadora del cuerpo femenino mediante una sobre-valorización de la maternidad, la cual es considerada como fuente de placer, conocimiento y poder específicamente femeninos. Esta perspectiva plantea la maternidad, en un sentido amplio, como sinónimo de un vínculo intrínseco y básico entre las mujeres, y al mismo tiempo intenta desligarla de las representaciones hegemónicas que aseguran la permanencia de la mujeres bajo el control masculino (Saletti, 2008). Es así que diversas autoras abogan por la «recuperación» de la maternidad, entendida como un elemento fundamental de la identidad y gozo femeninos frente a una maternidad sostenida y reproducida por el patriarcado, que oprimiría la experiencia de las mujeres en tanto madres.

A lo anterior también se suman nuevas perspectivas de corte ecologista y provenientes del saber experto que insisten en esta sobre-valorización de la maternidad como modo de 
acercarnos a lo natural. Por un lado, el llamado del ecologismo a transformar nuestros estilos de vida -escapando del consumismo con el fin de proteger a la naturaleza y mejorar nuestra calidad de vida- ha permeado hondo en muchas madres jóvenes, quienes ven en la maternidad una opción de cambio real ante esta situación. La filósofa francesa Elisabeth Badinter, en La mujer y la madre (2010), señala el nacimiento de una nueva figura, a la cual denomina "la buena madre ecológica», quien, concientizada sobre la degradación del medioambiente, se preocupa por tomar decisiones con el propósito de llevar a cabo una maternidad en armonía con lo ecológico y lo sustentable, lo cual implica, en cierto modo, «volver a lo natural».

En la actualidad, el discurso ecologista se vincula estrechamente con el discurso del saber experto, basándose en datos científicos para tratar de incidir en las decisiones de las mujeres madres. En las últimas décadas se han realizado diversas investigaciones que nos dan pistas sobre la importancia de alcanzar la simbiosis entre los hijos y sus madres (Iribarne, 2010). Para alcanzar dicha relación, muchas mujeres han optado por rechazar las técnicas hospitalarias tradicionales -la excesiva medicalización del parto a través de la cesárea, por ejemplo-, ya que las consideran el "desposeimiento» de sus cuerpos; tanto así que cada vez un mayor número de mujeres decide dar luz de manera natural, muchas veces en casa, sin médicos, pero siempre en compañía de una partera o doula ${ }^{1}$, denominación que cada vez se hace más conocida en nuestro país.

Por su parte, el auge del saber experto -o saber científico- se ampara en la identificación esencialista de la mujer y su capacidad de dar a luz, pues a lo largo de la historia occidental, el sexo femenino le ha impuesto una sola misión: tener hijos (Tubert, 2004). Este saber experto presenta una gran ambivalencia en torno a la cuestión maternal. Por un lado elabora la noción de «instinto maternal», el cual insiste en la maternidad como una actividad instintiva de las mujeres, como si fuese "algo" con lo que ellas nacen, algo genéticamente dado; mientras que por otro lado, diversas publicaciones del saber experto se dirigen hacia las madres como si ellas no supiesen cuidar a sus hijos, en este sentido, se refiere a ellas como «mujeres que deben ser educadas». El saber experto, especialmente proveniente desde la psicología, la nutrición y la pediatría, ha colaborado con la construcción de la madre como figura central en el cuidado de los hijos e hijas.

En consecuencia, Badinter (2010) acusa que en nuestras sociedades se ha producido un dramático giro en nuestra concepción de la maternidad, esto es, devolver la maternidad al centro del destino femenino. La maternidad, según esta autora, ha vuelto a estar de moda siendo objeto tanto de políticas públicas, como de la publicidad y el marketing. Ciertamente, esta situación implica un rebrote de los discursos que ensalzan la maternidad: hoy se venden y se auspician los privilegios y las ventajas del parto natural y

\footnotetext{
${ }^{1}$ Las doulas son mujeres, en su mayoría madres, que acompañan a otras mujeres en su camino hacia la maternidad. Su principal tarea consiste en brindar apoyo, tanto físico como emocional, durante el embarazo, el parto y el puerperio. Ser doula no requiere todavía una formación académica regulada, aunque sí poseen conocimientos sobre fisiología del embarazo y parto, de puericultura y lactancia.
} 
de la lactancia asociados a los placeres de la maternidad consciente, en una suerte de llamado a «volver a lo natural», «volver a lo esencial» (Del Olmo, 2013).

\section{Los grupos de crianza respetuosa}

En nuestro país los grupos de apoyo a la crianza respetuosa, a través de múltiples acciones y actividades colectivas ${ }^{2}$, aparecen como uno de los principales defensores del llamado a experimentar los placeres de la maternidad consciente $y$, a su vez, luchan contra el discurso biomédico hegemónico -entendido como la medicalización excesiva de la maternidad- reclamando volver a antiguas tradiciones como el parto natural, el colecho, el porteo y la lactancia a demanda, pensadas como formas saludables y naturales de entregar amor y afecto a nuestros hijos e hijas.

Muchas mujeres, no satisfechas con el estilo de crianza que permite el sistema socioeconómico neoliberal, se han comenzado a organizar en torno a diversas agrupaciones y colectivos, y hoy se constituyen como una emergente movilización social con la intención de recuperar el valor de las mujeres y de las madres, y así re-significar la maternidad. Los grupos de crianza se reúnen, "se condensan y solidifican cada vez más en virtud de objetivos compartidos, pero manteniendo siempre tal condición ciertamente líquida y netamente polifónica" (Massó, 2013, p. 178); efectivamente, no se trata de un todo homogéneo, sino más bien corresponden a una emergencia creciente de acciones colectivas y agrupaciones más o menos espontáneas. En Chile encontramos varias agrupaciones y talleres dedicados a la crianza respetuosa -tanto virtuales como presenciales-, articulados en torno a determinados objetivos compartidos ${ }^{3}$.

Es necesario señalar, además, que las mujeres que participan en estos grupos pertenecen a sectores socioeconómicos medios y altos, y en su amplia mayoría se trata de mujeres profesionales o estudiantes universitarias. Siguiendo a Bourdieu (2002), podemos decir que estas mujeres se encuentran próximas dentro del espacio social, en el cual circulan determinados significados culturales, creencias y valores relacionados con la maternidad, la familia, la pareja, el trabajo y las posibilidades de vida para las mujeres. De hecho, varias de estas mujeres, siendo profesionales, deciden dejar de trabajar (o hacerlo media jornada, o se atreven con algún tipo de emprendimiento enfocado en la infancia y la

\footnotetext{
${ }^{2}$ Estos grupos realizan charlas y talleres dedicados a mujeres madres con el objetivo de enfrentar la crianza de forma amorosa, a través de las técnicas del porteo, el colecho, la lactancia a demanda y el parto natural. Además, dichas agrupaciones han participado activamente en la difusión de la crianza respetuosa mediante distintas actividades dirigidas a la comunidad: expo-ferias en torno a la crianza sustentable y ecológica, la semana de la lactancia materna del año 2014, las concurridas «tetadas» colectivas en varias ciudades de la región a comienzo del año 2014, y la elaboración del proyecto de ley que busca asegurar la lactancia sin censura ni discriminación como derechos inquebrantables de niños, niñas y sus madres (BioBio, 2014; La Nación, 2014; Mamadre, 2014).

${ }^{3}$ En países como España y Francia, el fenómeno de los grupos de crianza respetuosa es mucho más conocido que en nuestro país, y lo es en parte porque se han abierto a espacios académicos relacionados al feminismo y ecologismo, en los cuales estos grupos han sido estudiados (Del Olmo, 2013).
} 
maternidad) para quedarse cuidando a sus hijos e hijas desde el hogar. Efectivamente, son mujeres que poseen un mínimo de libertad material para poder decidir, pero, además, estas mujeres cuentan con otros tipos de soportes, no sólo económicos, sino también y sobre todo sociales y culturales, como lo es contar con el apoyo y compañía de la pareja, la familia y los grupos de crianza, como espacios de solidaridad y contención.

\section{Aspectos metodológicos}

En términos metodológicos, esta investigación se basa en datos provenientes de cuatro grupos focales, con un total de 21 mujeres madres, quienes amable y entusiastamente decidieron ser partícipes de este estudio desarrollado entre los años 2014 y $2015^{4}$. El muestreo se realizó bajo la denominada Bola de Nieve, y el número de grupos se estableció por el criterio de Saturación (Valles, 2003). Es importante mencionar que los grupos focales fueron realizados en plazas y parques públicos de la región de Valparaíso, puesto que las mujeres deseaban ir con sus hijos e hijas como modo de «visibilizar la infancia y la maternidad». Estas mujeres se mostraron muy abiertas a participar debido a que en la presente investigación veían una buena oportunidad para "mostrarse» en espacios más académicos e institucionales, hasta el momento alejados de ellas. Es preciso agregar, además, que los nombres reales de las participantes fueron cambiados con la intención de proteger sus identidades

Frente a algunas perspectivas que ignoran al sujeto y otras que lo identifican como meros receptores acríticos del discurso, este artículo apunta a la importancia fundamental de analizar los discursos y sus implicancias para comprender lo social. De este modo, la categoría "discurso» adquiere gran relevancia teórica y metodológica. Asumimos que todos los objetos y las prácticas tienen un significado, siendo éstos contextuales, relacionales y circunstanciales. O dicho de otro modo: "todos los objetos y prácticas tienen un carácter discursivo porque es precisamente mediante su inserción en discursos particulares que los objetos y prácticas adquieren su significado e identidad" (Morales, 2014: 335).

Para analizar los datos utilizamos el enfoque teórico-metodológico de Análisis de Discurso. Esto indica que entendemos los discursos de las mujeres que participan en grupos de crianza como un conjunto de prácticas lingüísticas que mantienen y promueven ciertas relaciones sociales; en este sentido, el análisis "consiste en estudiar cómo estas prácticas actúan en el presente manteniendo y promoviendo estas relaciones: es sacar a la luz el poder del lenguaje como una práctica constituyente y regulativa" (Antaki \& Iñiguez, 1994: 63). Los discursos atañen significados, ideologías, poder y relaciones desiguales, debido a su ineludible "orientación hacia la acción»; es por eso que concebimos el discurso como una práctica social en sí misma, opuesta a la de actores neutros, con sus propios rasgos y consecuencias materiales; en suma, el discurso, más que «decir», «hace» cosas (Potter \& Wetherell, 1996).

\footnotetext{
${ }^{4}$ Tesis para obtener el grado de Licenciada en Sociología, Universidad de Valparaíso.
} 
A continuación, presentamos los tres discursos que construimos en base a los datos y categorías obtenidas a partir de los cuatro grupos focales.

\section{Articulando lo privado y lo político: la maternidad glorificada}

\section{Discurso La mujer como mamífera}

Este discurso plantea la necesidad de concebir la maternidad desde un punto de vista biológico, definiéndola como un aspecto trascendental en la vida de las mujeres. En este sentido, lo que este discurso hace es re-situar el lugar de definición de la mujer-madre, pues lo lleva al espacio de lo animal, de "lo mamífero», de modo que ser madre es ser hembra, huelga decir, es ser una madre que no abandona ni deja de lado a sus hijos, pues seguiría su instinto animal de cuidarlos tanto como sea necesario. Esta analogía con lo mamífero implicaría la legitimación de ciertas prácticas de cuidado infantil consideradas como «naturales» como, por ejemplo, llevar a los niños en brazos todo el tiempo -el porteo-, amamantar a los hijos cuando éstos así lo deseen -la lactancia a demanda- y dormir con ellos -el colecho-, entre otras. Se trata, entonces, de una visión no antropocéntrica de la maternidad, en donde hay una esencialización de la hembra-animal, situada por sobre la hembra-humana. Esta idealización del comportamiento mamífero olvida, por ejemplo, que existen algunas hembras mamíferas que abandonan a sus crías y que, incluso, algunas se las comen; por tanto, sólo rescata aquellas cualidades mamíferas que son consideradas puras y admirables. Al mismo tiempo, estas mujeres, en tanto hembra-animales, se sitúan por sobre el macho-hombre, olvidando nuevamente que «la naturaleza» brinda múltiples directrices respecto a los roles de hembra y macho en la crianza y cuidado.

"Nosotras como buenas mamíferas es instinto maternal, porque, por ejemplo, en la naturaleza hay hembras que solo buscan al macho para procrear y crían solas, dan a luz solas, o sea, sin ser egoísta ni menospreciar la figura paterna ni otras, la mujer tiene todas las herramientas para criar a un hijo, se la puede sola, se la puede y eso es lo especial" (Josefina)

La centralidad de la madre en las funciones de cuidado de sus hijos e hijas se apoya en tres elementos relacionados entre sí: el "amor de madre», la "actitud maternal» y el ya naturalizado «instinto materno». La «actitud maternal» sería una expresión de la maternidad que se manifiesta en algunas mujeres incluso antes de convertirse en madres. Dicha cualidad haría que la mujer sea más propensa a los cuidados, el amor y la protección, que los hombres, pues, estaría dotada de «algo especial» debido a su naturaleza específica. Por otro lado, el «amor de madre» se plantea como el mayor amor 
de todos, superando a cualquier otro tipo de amor, siendo éste más fuerte, más sano y más natural; se trataría de un amor incondicional y abnegado. Por último, el «instinto maternal» se propone como el más importante símbolo de exclusividad de la figura materna. Dicho instinto se caracterizaría por establecer una conexión especial entre la madre y su hijo o hija, una relación que implica conocer todo lo que sucede con ellos, su llanto, sus risas, sus caras, en suma, todo lo que los hijos quieren. Esta peculiaridad es la que principalmente diferenciaría a la mujer del hombre o, mejor dicho, a la madre del padre, posicionando a éste último, la mayoría de las veces, como mero «soporte» de la madre.

"Es que nosotras los tenemos en la guata, compartimos sus latidos, compartimos su respiración, su movimiento: somos un solo cuerpo. Y después cuando nacen, también estamos ahí pegadas con nuestra tetita y dándoles cariño, contención. Y los papás tienen que llegar como a inventarse todo eso, a inventarse una relación con sus crías (...) Nuestra relación es netamente biológica, pero después vamos desarrollando otras cosas también. Pero los papás no po. Los papás la van aprendiendo" (Andrea)

"Pero distinto es el instinto, porque si bien, mi compa fue súper comprometido, cien por ciento, pero hay muchas veces en situaciones que los dos no actuamos de igual manera, y es porque yo soy madre y él es padre, es tan sencillo como eso. 0 sea, él no lo tuvo en la guata, yo sí" (Eva)

"Antes no quería tener hijos, pero después de que nació el Balti (su hijo), todo cambió... lo del instinto maternal, el darles leche, porque siento que las mujeres estamos hechas pa esto: pa ser mamás, porque es heavy la conexión" (Cristina)

En consecuencia, estos argumentos realizan una sobre-valorización de la madre a partir de hechos biológicos, pues, como vemos, el cuerpo de la mujer desempeñaría un papel importantísimo en la relación espontánea y natural que se establece entre una madre y su hijo o hija. La gestación y el parto serían procesos fisiológicos y biológicos muy intensos, los cuales tendrían consecuencias emocionales muy fuertes en la vida de las mujeres: tener a los hijos en el vientre, ser la primera persona que los abriga y alimentarlos con la leche "que sale de una», establecería una relación indescriptible entre la madre y sus "crías", lo cual, en cierta forma, desconoce los efectos sociales y culturales que rodean a la maternidad.

\section{Discurso La «otra» maternidad}

Este discurso aparece como todo lo contrario a las características de la maternidad deseadas por las mujeres que participan en los grupos de crianza. Esta «otra» maternidad 
es interpretada como "todo aquello que no queremos ser», es decir, estas mujeres se posicionan en la vereda opuesta de los elementos que constituyen este discurso.

La "otra» maternidad es identificada a partir de dos "otredades»: una "tradicional» antigua- y otra más "contemporánea». La maternidad "tradicional» es aquella que experimentaron estas mujeres durante su niñez, o sea, se refiere a la maternidad de sus propias madres. Esta línea discursiva denuncia un excesivo autoritarismo y ausencia de ambos padres, resintiendo especialmente la de la madre. Cuestionan y culpan las malas prácticas de sus progenitoras, acusando que los rencores y traumas de ellas como mujeres y madres se deben a las inseguridades experimentadas durante la infancia Esta culpabilización de las progenitoras reproduce la tendencia en donde las madres son las responsables absolutas del bienestar o malestar de sus hijos e hijas, lo cual da lugar a las posiciones de «buenas» y «malas» madres. Esta ruptura intergeneracional consiste en una denuncia y toma de consciencia de dicha situación con el objetivo de no volver a repetir los errores del pasado y así poder generar un cambio. No obstante, esta ruptura, a pesar de innovadora, posibilita y permite la reproducción de ciertos estereotipos de género relacionados a la maternidad.

"Yo adopté esta forma de crianza porque, pa tener mejores seres humanos, más conscientes con su entorno, y diferente a cómo me criaron a mí, súper diferente, cachai. Y tampoco mala onda con mi mamá, pero es distinto po, cachai. Quizás si ella hubiera hecho muchas cosas diferentes pa mí serían mucho más fáciles otras cosas, cachai" (Vanessa)

"No sé, yo pienso en mí, en la crianza de mi mamá, que hoy en día no la critico tampoco, pero también fui en un momento una mujer llena de trancas, llena de miedos, de cuestionamientos, cachai, y ahora como que noto un cambio en mí, como que más natural, por así decirlo" (Cristina)

Por otro lado, la maternidad "contemporánea» cuestiona a la llamada «mujer moderna», aquella que intenta rendir por igual, sin mucho éxito, tanto en el trabajo como en las labores domésticas. Esta estrategia denuncia que muchas mujeres son madres por obligación, como forma de querer completar la vida, pero sin sentirlo realmente, es decir, sin ser conscientes de su maternidad, ya que el siguiente objetivo sería re-ingresar lo más pronto al trabajo y dejar a los hijos/as en la sala cuna o el jardín infantil. Se acusa que las mujeres se encuentran compitiendo con los hombres en el espacio del mercado laboral, en donde lo que se les ofrece no sería la tan anhelada independencia económica, sino la esclavitud del salario, puesto que si se quiere tener hijos/as éstos/as deben «encajar» en los ratos libres o bien externalizar su cuidado en niñeras o salas cunas.

"No sé, yo tengo una compañera, que la loca tuvo a su hijo porque se había casado, tenía una casa, ya, su hijo, pero la loca se fue a trabajar a los seis meses y lo mandó a 
una sala cuna. Y ella está todo el puto día en el trabajo, más encima ella vive en el interior. En el fondo está como dos horas, tres horas diarias con su hijo, cachai. ¿'Pa qué querís ser mama si esa va a ser...? Ella siguió su ritmo de vida igual, si bien, obviamente, lo incorpora, se van de vacaciones... pero ella sigue saliendo a carretear, o sea, está bien, yo también, pero si estai poco rato con tu hijo, cómo además no generai más espacios pa estar con él, cachai. Y si tú tenís un hijo, tú, de algo manera, adaptai tu vida pa estar con tu hijo. Él ya es parte de tu vida, no es un agregado que podai dejarlo todo el rato con otras personas" (Renata)

Las mujeres que participan en grupos de crianza consideran que para la «mujer moderna» el amor de madre se identificaría con tener un buen trabajo y dinero, lo cual se traduciría automáticamente en menos tiempo para poder disfrutar, conocer y educar a sus hijos e hijas. Por ende, se cuestiona duramente este tipo de maternidad ya que la prioridad no serían los hijos/as, sino la capacidad de generar dinero y mantenerse activa en el mercado laboral, lo cual reproduciría el modelo de sociedad neoliberal, y la maternidad consciente apunta, precisamente, a cuestionarlo. De este modo, implícitamente, se critica el modelo productivo propuesto para las mujeres -la compleja conciliación entre maternidad y trabajo, en el conocido postnatal de seis meses- puesto que éste no buscaría armonizar la vida familiar con la laboral, sino subordinar la primera a la segunda. Se critica la naturalización de la racionalidad económica en todos los ámbitos de la vida, pues ésta complicaría, estresaría y arruinaría la vida de los individuos, especialmente a las mujeres que desean dedicarse a sus hijos e hijas.

\section{Discurso Propuesta de sociedad}

Este discurso sitúa la maternidad como un "frente de lucha», lo cual implica cuestionarse la maternidad como nuevo espacio para la transformación social. De este modo, la «propuesta de sociedad» estaría compuesta por dos estrategias fundamentales, uno, empoderar a las mujeres en su labor materna y, dos, generar un cambio a nivel social, poniendo especial atención al cuidado del medioambiente y la educación de los nuevos ciudadanos/as.

Por un lado, una de las principales propuestas planteadas consiste en empoderar a las mujeres madres como sujetos de derecho, es decir, la autodeterminación de escoger el estilo de vida que quieren llevar, en este caso la maternidad. Este elemento aboga por la defensa de la sujeto madre para gestar, parir y criar con libertad a sus hijos e hijas; de este modo, este discurso lleva en sí la reivindicación de la figura de la sujeto madre.

"Y además tiene que ver con empoderar el rol de la mamá, que está súper mal visto en muchas ocasiones. Es como lo que pasa con los profes, que son indispensables para la sociedad, y a pesar de ser una labor súper importante pal' país, no tiene todo 
el respeto y apoyo que se requiere, y lo mismo sucede con las mamás que deciden criar ellas solas, a full, a sus hijos, es como onda "¿y no trabajai?", shi, qué más querís po" (Manuela)

Por otro lado, las mujeres que participan en grupos de crianza formulan una re-definición de lo social, de lo público: se intenta problematizar la maternidad como un espacio de acción para la transformación social. El objetivo sería participar en la construcción de una sociedad más justa, más humana y más natural a través del despliegue de otros valores como la diversidad, la empatía y la tolerancia, y también con pequeñas acciones en lo cotidiano para contribuir a mejorar la calidad de vida del planeta. Dichas acciones, relacionadas especialmente con los niños y niñas, implican diversas actividades de tipo ecológico como, por ejemplo, practicar la lactancia a demanda y así evitar el uso de mamaderas, usar pañales ecológicos porque producen menos desechos plásticos $y$, también, llevar una alimentación saludable y vegetariana, entre otros.

"Yo, personalmente, pienso que si querís criar un ser humano consciente con su entorno, tenís que mostrar reciclaje, tenís que mostrarle que en tu casa uno hace ladrillos ecológicos, no sé po. Esas cosas, cachai que son cosas chicas, pero en verdad son gigantes. Todo el plástico que uno junta es pa la cagá po" (Manuela)

El discurso «Propuesta de sociedad» reflexiona sobre la sociedad contemporánea, acusando que sus principales valores descansarían en el individualismo, el consumismo y la competencia, formándose así una sociedad narcisista, llena de miedos y trancas, todas ellas características nefastas para educar a niños y niñas. En este sentido, se justifica que el modo de criar a un niño/a es inseparable del tipo de sociedad en que nos gustaría vivir, por eso este discurso define y busca los efectos sociales de sus prácticas: criar a «los nuevos hombres, las nuevas mujeres», pues, para ellas lo personal también es político.

"En el fondo se trata de replicar en nuestros hijos el tipo de sociedad en que queremos que ellos crezcan, con amor, compañerismo, eso es lo que queremos todas las mamás, cachai, construir un mundo mejor pa ellos, con más alegría, menos golpes y castigos, pero sí más conversaciones y amor" (Rocío)

"Entonces yo creo que a eso apunta la crianza respetuosa, a construir un mundo más justo, y eso es súper bonito cachai... o sea, eh, es que en el fondo, vivimos en una sociedad súper loca po, en donde cada uno se las busca como puede, nadie mira pal lado, solo pa competir, se ha perdido ene el compañerismo, entonces, eh, en una sociedad así no quiero que crezca mi hija. Por eso, digo, apunto a una transformación social, pero desde dentro, desde el hogar, creo que esa sería nuestra diferencia, y cómo lo queremos lograr, criando gente feliz, gente sana, gente abierta de mente, por eso decía eso antes de reivindicar el papel de la mamá, porque al final de cuentas, ella es quien se lleva casi todo el mérito po" (Javiera) 
La madre consciente tendría en sus manos la posibilidad de participar en una "revolución», en una transformación no solo personal, sino también social. La maternidad constituiría un espacio privilegiado para la transformación social, lo cual implica que el rol materno debiese ser valorado con la misma intensidad. Sin embargo, aquello no ocurre. En la actualidad, se acusa que la maternidad no sería lo suficientemente valorada, siendo muchas veces, incluso, menospreciada por la sociedad. Muy por el contrario, lo que hoy se valoraría de manera positiva es el estereotipo de la «mujer moderna», es decir, aquella mujer capaz de ser exitosa no solo en el ámbito de las tareas domésticas y de cuidado, sino también el ámbito laboral y profesional, constituyéndose en el paradigma de los tiempos modernos.

\section{Reflexiones finales}

La maternidad se convierte un asunto relevante y de debate público no sólo debido a su indudable peso tanto en la historia personal de las mujeres como también en la historia contemporánea de las sociedades latinoamericanas, sino también por el rebrote de discursos maternalistas que intentan presentarla desde una posición emancipadora y política. En el presente trabajo nos propusimos abordar los discursos sobre maternidad de mujeres que participan en grupos de crianza de la región de Valparaíso, Chile, a partir de los cuales identificamos dos principales consecuencias, pues, como dijimos anteriormente, los discursos más que «decir», «hacen» cosas.

En primer lugar, y desde una perspectiva de género, evidenciamos una «reproducción de roles tradicionales de género». Específicamente, en los discursos "La otra maternidad» y "La mujer como mamífera» emergen diversas estrategias que identifican la maternidad como algo propio de lo femenino, es decir, como una "etapa de hay que vivir»: se trata de articulaciones que, efectivamente, dan cuenta de la maternidad y las tareas de cuidado y crianza de hijos e hijas como una función específicamente de las mujeres, pese a la incorporación de los hombres en las tareas parentales.

En este sentido, se puede concluir que la maternidad sigue siendo fundamental a la hora de construir la identidad de género femenina. Las mujeres de los grupos de crianza, antes que todo, se autodefinen como "hembras» y como "madres». Sin embargo, pensamos que cuestionar y desmitificar la maternidad es un reto clave para las ciencias sociales y la teoría feminista, pues el significado que adquiere la maternidad sigue siendo una de las principales causas del reparto desigual de las tareas para hombres y mujeres. Como vemos, persiste aún el peso de una cultura patriarcal, en donde la maternidad se posiciona como el fin supremo de todas las mujeres. A lo largo de la historia occidental, maternidad y feminidad se han identificado hasta el extremo, hasta el punto de considerarse la maternidad como «esencia» de lo femenino (Montecino, 2001); en 
nuestras sociedades se ha naturalizado la idea de que "ser mujer es ser madre», transformando, por consiguiente, uno de los aspectos de las mujeres en el todo.

A nuestro modo de ver, la reproducción de la identidad tradicional de género femenina se ve con mayor claridad en la idea de llevar a cabo una "maternidad intensiva», lo cual implica dejar de trabajar remuneradamente para poder dedicarse de lleno a los hijos e hijas. Desde enfoques feministas más críticos, esta nueva tendencia -el modelo de la "maternidad intensiva»- no hace sino prolongar el lugar tradicional de la mujer en el hogar, es decir, al plano de lo doméstico y lo afectivo debido a su «naturaleza» específica. Sin embargo, lo anterior es posible solo en la medida en que la maternidad sigue siendo una fuente de legitimación y de identidad femenina: si las mujeres siguen defendiendo relaciones privilegiadas con el orden doméstico, sentimental o estético, "ello no se debe al 'simple' peso social, sino a que éstos se ordenan en la actualidad de manera tal que ya no suponen un obstáculo para el principio de libre posesión de uno mismo y funcionan como vectores de identidad, de sentido y de poderes privados" (Lipovetsky, 1999: 11). Evidentemente, la preponderancia de la mujer en roles domésticos puede leerse a la luz de la reproducción de identidades de género, no obstante, ello no implica reducir el fenómeno a esa función unívoca, pues el compromiso femenino con el ámbito de lo privado trae consigo formas de poder, que pese a ser privadas no por ello tienen menor importancia: las tareas domésticas suponen modos de construir territorios identitarios y personales, para imponer los propios criterios y el modo particular de actuar y de pensar, reivindicando así modos «propios» de ordenar, cuidar, alimentar y criar.

Desde algunas corrientes feministas más críticas se observa con cierta suspicacia estas nuevas reivindicaciones de la maternidad, pues se cree que todo aquello no es más que un nuevo intento de capturar a las mujeres en una renovada «mística de la feminidad» ${ }^{5}$. No obstante, pensamos que es imprescindible ir más allá, pues lo anterior impide pensar en la maternidad consciente y en la maternidad intensiva como argumentos válidos capaces de apostar por un cambio social. Ciertamente, pensamos que se trata de un asunto más complejo y que tiene que ver también con el hecho de hacerse cargo de algunos problemas fundamentales de las sociedades actuales, como lo es cuidar a nuestros hijos e hijas. Si bien consideramos importante detectar elementos regresivos y conservadores en sus discursos, también es relevante detectar aquellos elementos radicales y más críticos que sería ingenuo menospreciar.

De este modo, constatamos una segunda consecuencia o función en los discursos de estas mujeres, a saber, "la resistencia que plantean al orden social dominante». De los analizados, «Propuesta de sociedad» apunta a dicha dirección, pues, a través de interesantes estrategias tienden a cuestionar el orden social, proponiendo, al mismo tiempo, la maternidad como «frente de lucha» desde el cual se puede generar los cambios

\footnotetext{
5 "La mística de la feminidad" (1963), de Betty Friedan, libro clave del feminismo estadounidense que denuncia el agobio de las mujeres de clase media dedicadas al cuidado del hogar y sus familias.
} 
que la sociedad contemporánea necesitaría, es decir, a través de la resignificación de las funciones maternas.

De lo anterior se desprende que el modo de cuidar a un niño o niña es inseparable del tipo de sociedad en la que nos gustaría vivir. Como señala la antropóloga Mary Douglas en Estilos de pensar, a través de cualquier elección que hagamos, por banal que nos parezca, expresamos modos de razonar y de pensar que tienen efectos sociales, y que contribuyen a conformar un tipo de sociedad determinada (en Varela, 2014). Prácticas tales como el reunirse entre madres, el porteo, el colecho y la lactancia a demanda, entre otras, se proponen como "prácticas cotidianas de resistencia», es decir, prácticas de oposición a una realidad maternal impuesta por la sociedad. Se trata de pequeños cambios con el objetivo de generar nuevas prácticas y modos de «ser madre».

Los grupos de crianza avanzan problematizando la maternidad y lo que implica ser madre hoy en día. A través de un análisis crítico de la sociedad, las mujeres que participan en estos grupos otorgan un significado político a lo que hasta ahora era considerado dentro del ámbito de lo privado, asumiendo la premisa «lo personal es político» como una verdadera bandera de lucha. De este modo, argumentan que las resistencias a nivel «micro» son necesarias para producir las condiciones de acción política a nivel «macro», y con ello lograr cambios concretos en la sociedad.

Con todo lo planteado, podemos señalar que la propuesta de estas mujeres tiene un fuerte contenido emancipatorio: puesto que valorar el papel subyugado de las mujeres madres y visibilizar a niños y niñas constituyen actos efectivamente feministas, en tanto las mujeres y los niños/as han sido reducidos a lo doméstico. Esta propuesta es éticamente interesante en cuanto el valor principal es la responsabilidad y el cuidado de los otros, todo ello enmarcado en una ética del cuidado. La ética del cuidado se basa en la relación amorosa, en la compasión y en la responsabilidad por los otros, valores que han sido históricamente desarrollados por las mujeres. Asimismo, la ética del cuidado guarda relación con la idea radical, pero no por eso menos verdadera, de que toda existencia humana es posible en tanto hubo un otro que se hizo cargo de nosotros cuando éramos completamente vulnerables sin exigir nada a cambio. En este sentido, ese hacerse responsable del otro sólo por conocer su existencia es una propuesta ética radical. Sin embargo, el problema es justamente ¿por qué ese trabajo deben realizarlo mayoritariamente las mujeres? Con ello pensamos que se retorna a una propuesta conservadora: que las mujeres sí serían diferentes de los hombres no sólo respecto a sus aspectos fisiológicos, sino también y, sobre todo, respecto a sus valores principales.

Asociar el ser mujer con el ser madre, y definir la maternidad como el aspecto fundacional de la identidad femenina, son creencias muy arraigadas en el imaginario colectivo. No obstante, debemos recordar siempre que la ecuación «mujer=madre» no corresponde a ninguna esencia natural, sino más bien se trata de una construcción histórica y social, por lo tanto susceptible de ser modificada. En suma, la maternidad en occidente se trata de 
una categoría esencialista que homogeneiza a todas las mujeres sin tomar en cuenta sus ideas o intereses personales; por eso, apuntamos por la deconstrucción de esta representación.

\section{BIBLIOGRAFIA}

Antaki, C. \& Iñiguez, L. (1994). El análisis del discurso de psicología social. Boletín de Psicología, núm. 44, pp. 57-75.

Badinter, E. (2010). La mujer y la madre. Un libro polémico sobre la maternidad como nueva forma de vida. Madrid. Esfera.

Bourdieu, P. (2002). Capital cultural, escuela y espacio social. Buenos Aires: Siglo XXI.

Del Olmo, C. (2013). ¿Dónde está mi tribu? Maternidad y crianza en una sociedad individualista. Buenos Aires: Capital Intelectual.

Dietz, M. (1987). El contexto es lo que cuenta: feminismo y teorías de la ciudadanía. Daedalus, núm. 6, p. 105-130.

Fernández-Rasines, p. (2001). Afrodescendencia en el Ecuador. Raza y género desde los tiempos de la colonia. Quito: Abya-Yala.

Germani, G. (1965). Política y sociedad en una época de transición: de la sociedad tradicional a la sociedad de masas. Buenos Aires: Paidós.

Iribarne, M. (2010). Discursos sobre la maternidad científica. Una perspectiva crítica. Investigaciones Feministas, vol. 1, p. 193-212.

Lavrin, A. (2005). Mujeres, feminismo y cambio social en Argentina, Chile y Uruguay (18901940). Santiago de Chile: Dirección de Bibliotecas Archivos y Museos, Centro de Investigaciones Diego Barros Arana.

Lipovetsky, G. (1999). La tercera mujer. Barcelona: Anagrama.

Massó, E. (2013). Lactancia materna y revolución, o la teta como insumisión biocultural: calostro, cuerpo y cuidado. Dilemata, año 5, núm. 11, p. 169-206.

Molyneux, M (2003). Movimientos de mujeres en América Latina. Estudio teórico comparado. Madrid: Cátedra. 
Montecino, S. (2001). Madres y Huachos. Alegorías del mestizaje chileno. Santiago de Chile: Editorial Sudamericana.

Morales, M. V. (2014). Discurso, performatividad y emergencia del sujeto: un abordaje desde el post-estructuralismo. Athenea Digital, núm. 14, p. 333-354.

PNUD (2010). Género: los desafíos de la igualdad. Santiago de Chile: PNUD.

Potter, J. \& Wetherell, M. (1996). El análisis del discurso y la identificación de los repertorios interpretativos. En: A. Gordo y J.L. Lizana (Comp.): Psicologías, discursos y poder (PDP), p. 63-78. Madrid: Visor.

Saletti, L. (2008). Propuestas teóricas feministas en relación al concepto de maternidad. Clepsydra, núm. 7, p. 169-183.

Tubert, S. (2004). La maternidad en el discurso de las nuevas tecnologías reproductivas. En: A. de la Concha \& R. Osborne, (Coords.): Las mujeres y los niños primero. Discursos de la maternidad, p.11.138. Barcelona: Icaria.

Valladares, B. (1994). Revisión teórica sobre los mitos de la maternidad. Ciencias Sociales, núm. 65, p.67-74.

Valles, M. (2003). Técnicas Cualitativas de Investigación Social. Madrid: Síntesis.

Varela, J. (2014). Reseña ¿Dónde está mi tribu? Maternidad y crianza en una sociedad individualista. De Carolina del Olmo. Teknokultura: Revista de Cultura Digital y Movimientos Sociales, vol 11, núm. 1, p. 219-222.

Zarco, A. (2011). Maternalismo, identidad colectiva y participación política: las Madres de Plaza de Mayo. Punto Género, núm. 1, pp. 229-247. 